\title{
UNDERSTANDING URBAN DISASTER RESILIENCE THROUGH A MORPHOLOGICAL APPROACH: A CASE STUDY OF SETTLEMENT UPGRADING AND FLOOD RESPONSE IN BANGKOK
}

\author{
Pamela Sitko* \\ Avar Almukhtar**
}

\begin{abstract}
A city can be difficult to analyse. However, approaches such as urban morphology (the study of urban form) can assist with understanding what the city is by reflecting how urban form is influenced by interdependent social, governance and economic factors that contribute to building resilience. To illustrate how urban morphology can be used as an approach for understanding disaster resilience in cities, a case study of informal settlement upgrading impacted by a flood in Bangkok, Thailand is presented. A study of the Bang Bua Canal in Thailand's capital city is used throughout the paper to demonstrate how disaster resilience can be analysed by using four morphological layers. The paper identifies key dimensions of resilience within each morphological layer. The dimensions highlight patterns of social, governance and economic influence on the built environment. Generalisable lessons from using morphology as an approach for understanding disaster resilience include: that resilience can be a way of building upon the existing capacities of low-income neighbourhoods; the concept is a positive when it helps neighbourhoods 'bounce forward' and that, crucially, resilience can act as a bridge between development and disasters.
\end{abstract}

Keywords: Disaster, resilience, urban morphology, Bangkok, upgrading

\section{INTRODUCTION}

Cities are diverse, dense and complex. Represented by only two percent of the earth's land, cities host over fifty per cent of the world's population (Allen et.al., 2012) generate eighty per cent of global gross domestic product (GDP) (World Bank, 2015) and are responsible for seventy per cent of global energy consumption (UN-Habitat, 2011). By 2050, it is estimated that sixty six per cent of the world's population will be urban, with as much as ninety per cent of the increase in urbanisation taking place in Asia and Africa (United Nations Department of Economic and Social Affairs, 2014).

Initially this paper describes the methodology, it then defines urban disaster resilience, after which it presents the ways in which urban morphology can inform our understanding of disaster resilience. In section five, four morphological layers are analysed through the case study and key dimensions of disaster resilience. Generalisable lessons are provided in the concluding remarks that explain why morphology is a useful approach for understanding urban disaster resilience.

\section{METHODOLOGY}

This paper is a presentation of qualitative and morphological data analysis following a literature review of academic papers and grey literature such as assessments, evaluations and lessons learnt reports from non-government organisations (NGOs). Key informant interviews were held with fifty people from aid agencies (international and local, agencies from the United Nations), government, think tanks, academia, the private sector and the media. A total of ninety one semistructured interviews were undertaken with people from the three neighbourhoods. The key informant interviews and FDGs were coded using NVivo software in order to identify patterns within the data. The findings for each morphological layer were then presented to neighbourhood residents from the case study through seven focus group discussions (FDGs) in order to validate the findings.

\section{DEFINING URBAN RESILIENCE}

Resilience (Sanderson and Sharma, 2016), is a newer manifestation of many years of holistic development and disaster management thinking. Within the concept of resilience one can see echoes of concepts such as the livelihoods approach, which combines analysis of chronic stress (reoccurring stressors that reduce one's ability to cope)

* Dr Pamela Sitko, World Vision International, Sydney, Australia.

Email correspondence: Pamela.Sitko@gmail.com

** Avar Almuhktar, Oxford Brookes University, Oxford, UK.

Email correspondence: avar.almukhtar@gmail.com 
and disaster shocks (Scoones, 1998). The concept of Linking Relief, Rehabilitation and Development (LRRD), which focuses on the links between short-term humanitarian assistance and longer-term development interventions (Buchanan-Smith and Fabbri, 2005) is also present. Other attempts to bridge disasters and development thinking are also present in resilience such as disaster mitigation and preparedness (DMP), a concept concerned with minimising the effects of disasters while taking precautionary measures to prepare for risk (Christoplos et.al., 2001) and disaster risk reduction (DRR), policies and practices that prioritise longterm prevention (Twigg, 2015).

The appeal of resilience is its diverse application. Tanner et al.,(2015) argue that the broad applicability of resilience is precisely what makes it a difficult concept to operationalise. Based on that critique, this paper finds it is crucial to define resilience for whom, and to what, as a means of clarifying the concept. Defining resilience for whom is important when interrogating resilience in cities because one hazard such as flooding, may identify traditionally vulnerable groups i.e. people living in low-income settlements on a canal bank, while another hazard such as earthquakes, may identify some non-traditional groups i.e. middle class people who build multi-storey homes without adhering to building codes.

Resilience has a history of being criticized for promoting the status quo by enabling communities to 'bounce back' (Twigg, 2009). Some scholars believe that bouncing back and maintaining the same core functions can be reckless, and sometimes even dangerous, when the status quo is one of corrupt governance, flailing economic policies and restricted civil rights (Pelling, 2011). When the state of return is undesirable, transformation is sometimes suggested as an alternative. Therefore, proponents of resilience prefer to talk about 'bouncing forward', suggesting disasters as a potential opportunity (Folke, 2006) for adaptation to future risk.

Another advantage of resilience is the opportunity it affords people to build upon what already exists. Resilience frames problems in a positive light while concepts like disaster risk reduction imply a need to 'reduce'. Perhaps one of the biggest arguments in favour of resilience is the way in which it has the potential to bridge disaster and development paradigms. Resilience, it can be argued, is a cost-effective way to save lives and protect development gains, thereby integrating two paradigms (Combaz, 2015). This paper argues that in order to be effective, resilience ought to be built both before and after a disaster, and that the disaster itself is a test of how the built environment has learned from history to cope with and adapt to shocks and stresses.

\section{URBAN MORPHOLOGY'S COMPLEMENTARITY TO DISASTER RESILIENCE}

In this paper, urban morphology is defined as the study of urban form and the actors and processes that shape it (Almukhtar, Forthcoming). The primary concern of urban morphology is to create an understanding of the evolution of form in order to guide appropriate future adaptations and transformations of the built environment based on people's social, economic and governance needs.

Through a disaster resilience lens, urban morphology can be used to investigate patterns of vulnerability, capacity, risk and opportunity (Sitko, 2016b). Within those patterns, morphology enables the identification of social, economic and governance factors that influence and shape the built environment. Identifying the factors provides neighbourhood residents, urban planners and designers, humanitarian and development actors, various levels of government, the private sector and other urban stakeholders with entry points for transforming the city in ways that build resilience. Urban morphology compliments, and perhaps even strengthens, the concept of disaster resilience in three key ways described below.

\section{Memory}

Urban morphology engages with history, seeking to draw connections between historical and modern day transformations at different scales and resolutions of urban form in order to identify underlying factors that shape a place (Warner and Whittenmore, 2012). Without morphology, resilience does not have a memory of what it is bouncing 'back' to or 'forward' from. When components of a neighbourhood or city are analysed through morphology, it allows people to judge the patterns as positive or negative, useful or impeding, equitable or oppressing among other things in order to identify where transformations could occur.

\section{Scale}

Urban morphology provides the opportunity to study patterns of vulnerability, risk and capacity at scale, revealing different degrees of power dynamics and control by a plethora of actors. Power and the types of internal conflicts revealed are different at various scales of analysis (Massey, 1993). Who is and is not included in decision-making bodies is a strong indication of power relations that influence the wider geographical context. 
Time

Time, an essential element of urban morphology, may go some way in explaining changes in resilience across different cultural contexts at different scales over time. The temporal changes in a city can be identified by looking in particular at changes in maps and town plans as they transform across different periods of time. Triangulating changes across scale and time provides a better understanding of human settlements (Kropf, 2009) and is particularly important in research in low-income settlements where power dynamics often force poorer people to live on marginalized land with a number of natural and man-made risks.

In summary, urban morphology offers an understanding of scale, time and history, providing granular details about the influences that shape urban form. When viewed from a resilience lens, morphology can be seen as a holistic approach to disaster prevention and mitigation that builds upon existing capacities instead of focusing on vulnerability reduction through a disaster risk reduction lens.

\section{MORPHOLOGICAL LAYERS}

The layers of urban form used in this paper to identify patterns of vulnerability, capacity and risk are topography, public open space networks, plots and buildings. These layers study urban form at different scales of resolution, acknowledging that each layer changes at different rates across time with topography seeing the slowest changes (across centuries) and buildings seeing the fastest rate of change (across intervals as shorts a months and years). Figure 1 shows the four morphological layers used in this case study.

Morphological analysis highlights changes within the built and natural environment. Morphology analyses the quality of the urban built and natural environment, and serves as the basis for asking, how did the neighbourhood become what it is today and what are the key patterns of change that can be identified? To this end, urban morphology, when used as an approach for understanding and building urban disaster resilience, can address the critique by Levine et al. (2012) that resilience lacks a historical dimension, which leads to mistakes being repeated. Urban morphology is an approach that can help build a memory of capacity, vulnerability and risk. The case study below is used to explain how disaster resilience can be analysed within each morphological layer.

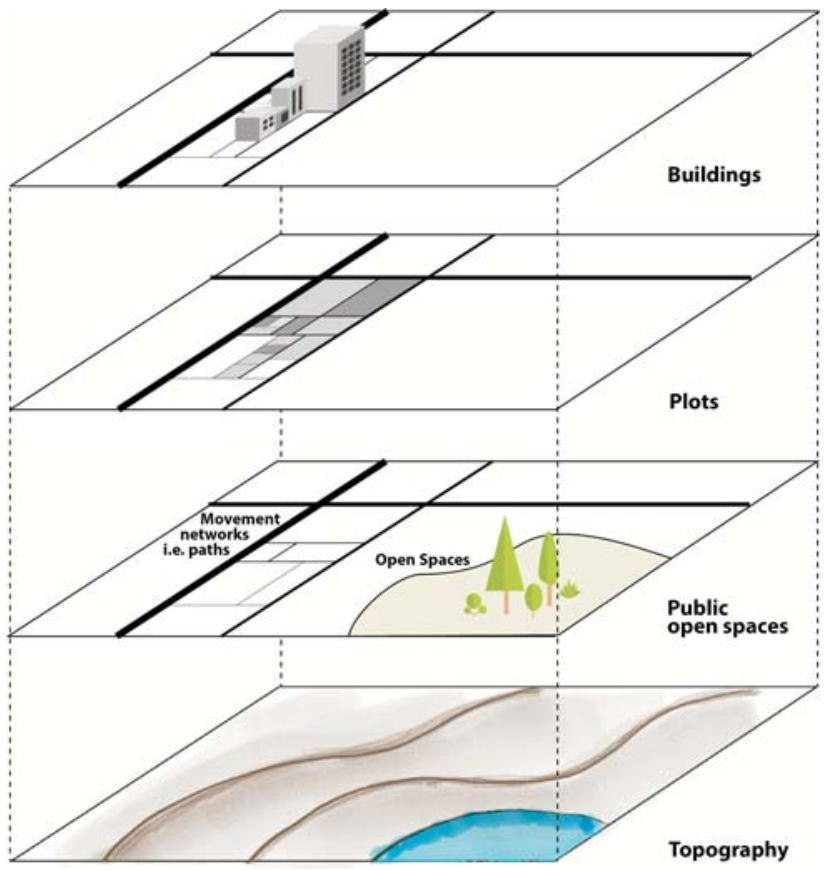

Figure 1: Morphological layers

\section{Topographical Layer}

Topography is the largest and the most permanent morphological layer where changes take place across centuries, and is considered the basis for influencing change in other morphological layers due its ability to influence a city's layout. The topographical layer is investigated first because it is comprised of macro landscape features observable in nature such as land, water and other notable features of a specific terrain (Bolio Arceo, 2012), including pre-urban structures. Analysing the topographical layer means examining large-scale historical changes and influences on physical topography over time (Conzen, 2010). The topographical layer is important when analysing disaster resilience because it accounts for changes in climate and the resultant hazards and risks, such as drought and flood cycles.

\section{Dimensions of disaster resilience within the topographical layer}

The topographical layer reveals two dimensions of disaster resilience in the Bang Bua Canal. These two dimensions are not necessarily positive and require transformation over time to build a safer environment. The dimensions are: a pre-disposition to flooding, and weak governance. 


\section{The Bang Bua Canal Case Study}

The Bang Bua Canal is located in northern Bangkok on a three-kilometer stretch of land where settlement upgrading opportunities were offered to 12 neighbourhoods with an estimated 17,000 people. The National Treasury Department owns the land and 2004 communicated plans to evict Bang Bua Canal residents in order to construct a new highway to alleviate growing traffic congestion. The eviction was expected to decrease flooding downstream, which was being blamed on river-based houses for restricting the flow of water. Increasing levels of water pollution were also blamed on canal dwellers due to the practice of dumping untreated sewage and wastewater directly into the canal.

Eviction was avoided by joining the national government's slum and squatter upgrading programme, Baan Mankong, which translates as 'secure housing' (Wungpatcharapon and Tovivich, 2012). Each of the neighbourhoods participating in the Baan Mankong upgrading programme agreed to three conditions: to form a neighbourhood savings group and then register as cooperative; for the cooperative to pay rent for the land; and for the houses to move off the canal and onto proper land.

In 2011 a flood struck Bangkok, impacting the Bang Bua Canal. The activities undertaken in the upgrading determined the effectiveness of each neighbourhood's response to the flood. While each of the neighborhoods had its own challenges and successes in the upgrading and flood response, some generalisations about the overall disaster resilience of the canal can be made by exploring patterns of vulnerability, capacity and risk common to the neighbourhoods there.

Figure 2: A description of the Bang Bua Canal settlement upgrading and flood response case study in Bangkok, Thailand.

\section{i. Pre-disposition to flooding}

Topographical analysis of Bangkok shows that historically Bangkok has a pre-disposition to flooding thereby creating a complex web of risk and exposure in present day Bangkok. Bangkok is rooted in an agricultural past of rice farming (Roachanakanan, 1999). Much of the delta city is below sea level (World Bank, 2010), with some parts as low as 1.5 meters (Philip, 2011). This results in seasonal flooding, which was traditionally utilised in annual rice farming. Throughout Bangkok's history, its canals were used as domestic water sources, a method of irrigating paddy fields and as a means of transportation (Roachanakanan, 1999). Over the years, new canals were dug, accompanied by dikes and levees designed for flood prevention (Roachanakanan, 1999). Analysis of the topographical layer suggests that Bangkok's history of flooding may continue with climate change, rising sea levels, coastal and soil erosion, as well as shifting clay soil all of which are modern ecological threats that expose the city to flood risk.

\section{ii. Weak governance has increased exposure to floods}

Over the years, Bangkok's natural environment has been shaped by weak governance networks that have increased exposure to floods. For example, a significant number of canals are now home to poorer people encroaching on canal banks or have been filled and turned into roads (UNESCAP, 2014). Urbanisation has decreased the percentage of permeable surfaces that can absorb rainfall. Decades of weak urban planning and lack of enforcement of land use regulations has led to the uncontrolled growth of underserviced neighbourhoods such as informal settlements (UNESCAP, 2014).

\section{Public open space network layer}

The second morphological layer in this discussion is the public space network layer. It investigates public open spaces used for movement such as highways, streets, small pedestrian lanes and water channels. The design of movement networks has the potential to impact the safety and permeability of an area while increasing or decreasing connectivity (Almukhtar, 2016). Today, many of those living along the Bang Bua Canal are daily wage earners, such as vendors, labourers, shop assistants and to a lesser extent, government, military and office workers (Wungpatcharapon and Tovivich, 2012). The canal's population rapidly grew when the first international airport was built in Bangkok, which acted as an economic driver, attracting migrant workers and transforming paddy fields into highways.

The public space network layer also analyses open spaces used by the general public for social and economic activities (Carmona et.al., 2003). Open spaces can be formal or informal and include squares, playgrounds, parks and market places (Kropf, 2013). Analysis of the public open spaces layer identifies how patterns of use have evolved over time, the innovative trade-offs between private and public space (Dovey and King, 2011), the types of people who use public spaces and the risks and opportunities they face in crisis and non-crisis periods. Today, the Bangkok Metropolitan 
Authority (BMA) considers the space along the Bang Bua Canal 'open space' or 'green space' where building is not permitted. However, much of the open space around the canal has been taken over by low-income housing settlements due to a lack of enforced planning laws.

\section{Dimensions of disaster resilience within the movement networks and public open spaces layer}

The movement networks and public open spaces layer reveals three dimensions of disaster resilience in the Bang Bua Canal: safety, inclusivity and income generation.

\section{i. Safety}

The upgrading process prioritised the creation and improvement of roads and public open spaces, which contributed to an overall greater sense of safety and security in the Bang Bua Canal. For example, major pedestrian lanes were introduced while others were expanded, creating more permeability. Installation of street lights provided better visibility. Smaller alleys were designed with a high degree of connectedness to the major pedestrian lane in two of the neighbourhoods, arguably contributing to safety by increasing footfall in previously isolated areas. Jacobs (1961) writes that public peace is kept by the public itself through people having 'eyes on the street' when there is 'continuous use', which turns human activity into interesting activity to watch. In terms of public open spaces, the right to play in safe, child-friendly spaces was prioritised through the design of public open spaces at the centre of all three neighbourhoods. Prior to the upgrading children used to play in parking lots, at risk of vehicular related accidents and within reach of strangers.

\section{ii. Inclusiveness}

Social inclusion is the second dimension of disaster resilience identified within the public open spaces layer. The increase in pedestrian lanes also increased the capacity for socialising. Canal dwellers parked their motorcycles in pockets of open space when visiting one another and often sat on street furniture observing neighbourhood activities. The neighbourhoods with public open spaces at their centre became more inclusive for children and their elderly caregivers who could walk short distances to gather, socialise and supervise younger children.

\section{iii. Income generation}

The pedestrian lanes better enabled neighbourhood residents to generate income; therefore, income generation is included as the third dimension of disaster resilience at the movement networks and public open spaces layer. More pedestrian lanes resulted in an increase of vendors accessing the area with goods to sell. Some residents used portions of the road for storing goods related to income generation, such as vending carts or materials for recycling.

In summary, thoughtfully designed and well maintained pedestrian lanes and public open spaces can become a panoply of social and economic activities that promote safety, inclusivity and generate income for users, demonstrating key dimensions of urban disaster resilience.

\section{Plots}

Once movement patterns have been established, plots begin to appear (Koster, 1998), hosting people living or working on parcels of land (Whitehand, 2001). Plots are defined by land use and their physical form (Kropf, 2009). It is widely recognised that many towns and cities lack regulated plot dimensions (Whitehand, 2001), and thus they vary in shape and size. Since plots are usually objects of ownership, analysis of ownership and control provides an essential insight into socially defined relationships between the controller and the user (Kropf, 2009). It can be helpful to analyse plots as a separate layer when studying urban disaster resilience in order to identify changes in access to and quality of a piece of land, its use and ownership. In the case of the Bang Bua Canal, analysis of the plots layer reveals three key dimensions of disaster resilience.

\section{Dimensions of disaster resilience within the plots layer}

The plots layer reveals three dimensions of disaster resilience in the Bang Bua Canal: land tenure, governance structures and social capital.

\section{i. Land tenure}

The first dimension is secure land tenure. In the Bang Bua Canal, chronic stresses and sudden shocks prompted the need for canal residents to rethink tenure security. In late 2000 , twelve neighbourhoods illegally squatting on the land owned by the national government were threatened with eviction. After a great deal of negotiation, the twelve neighbourhoods were offered the opportunity to rent the land from the national government and participate in an upgrading scheme. The neighbourhoods that agreed to pay rent for the land invested the most financially in buildings, roads and public spaces because of their legally binding 
contract that grantees the neighbourhood's permanence.

\section{ii. Governance structures}

The second dimension of disaster resilience within the plots layer is governance structures, which links very strongly to land tenure. The case study shows that governance structures are most successful when they are transparent, accountable and equitable, regardless of whether they are formal or informal. The upgrading required fair leadership. In some neighbourhoods new governance structures formed and displaced old power structures. In one particular neighbourhood, the new power structure was built on a conflict of interest with a husband standing as the formal elected leader of the neighbourhood, his wife as the leader of the upgrading activities and their daughter as the accountant of both structures. In a different neighbourhood, the introduction of the upgrading created two separate and often antagonistic governance structures - those who opted in for the upgrading and those who were against it. In a third neighbourhood (potentially the largest of the twelve) transparent, equitable governance structures resulted in strong social cohesion between the leadership team and neighbourhood residents. Land sharing was agreed to within a period of one year of negotiations in this neighbourhood all home upgrading activities were completed within two years.

\section{iii. Social capital}

The third dimension of disaster resilience identified at the plots layer is social capital. Here Archer's (2009) theory of three levels of social capital - bonding, a function of intracommunal relations; bridging, inter-communal relations; and linking, a function of community relations with the State - offers a means for understanding the ways in which social capital impacted the plots layer.

The first level of social capital, 'bonding', is evidenced most when neighbourhoods worked together to plan new pedestrian lanes, redistribute plots of land and develop public open spaces. Each neighbourhood also created its own social welfare system to assist families whose financial assets were depleted. The 'bridging' form of social capital, a horizontal linkage between neighbourhoods within the canal, is demonstrated through what is known as the Bang Bua Canal Network. The twelve neighbourhoods in the Canal Network worked together to reduce river pollution and start anti-drug campaigns in an effort to reduce drug use and trade in the area. Evidence of the 'linking' form of social capital whereby the Canal Network or neighbourhoods link with the State was observed when leaders from low-income settlements across Thailand visited the Bang Bua Canal in order to undertake peer learning about the multiple approaches and challenges of upgrading.

In summary, the plots layer demonstrates that plot transformation occurs when land tenure is secure; a transparent and accountable governance system is in place and strong social dynamics drive bonding at different scales.

\section{Buildings and services layer}

Finally, the buildings and services layer is the most rapidly changing of the physical layers, and arguably one of the most fundamental layers in morphological analysis for understanding the social, political and economic factors that influence a neighbourhood (Bolio Arceo, 2012; Whitehand, 1987). So important are infrastructure and services, that UN-Habitat describes them as the 'bedrock of prosperity' in its 2012-2013 State of the World's Cities Report, arguing that 'inadequate infrastructure is a major impediment to the prosperity of cities' (UN-Habitat, 2013, p.xvii). Traditional approaches to analysis of the building layer includes mapping the types of building in order to ensure future urban development takes into account historical transformations and cultural traditions (Whitehand, 2001). While this is important, the main focus of analysing buildings and services in relation to urban disaster resilience is to ascertain opportunities for improving quality of life and well-being. According to UN-Habitat (2013), access to adequate housing and residential services promotes competiveness and economic growth; improves urban connectedness; reduces poverty and contributes to safer, more sustainable cities. Investing in, and maintaining critical infrastructure and services is listed by UNISDR (2015) as one of ten essentials in its "Making Cities Resilient" campaign.

\section{Dimensions of disaster resilience within the buildings and services layer}

The quality of buildings, access to financial capital and planning and reconstruction processes at a macro level are identified as key dimensions of disaster resilience in the buildings and services layer. 


\section{i. Building quality and the politics of participation}

In neighbourhoods, housing accounts for the majority of the typologies of buildings (Arendt and Alesch, 2015). In the Bang Bua Canal, homes that were single storey, built on stilts and containing wooden flooring and walls were most vulnerable to flooding, and in the 2011 flood such houses were completely destroyed. The poor quality of building materials can be traced back to financial vulnerability inexpensive building materials such as bamboo, corrugated iron and timber are often used to cope with the weather, offer privacy and accommodate construction on marginalized land.

Meanwhile, well constructed two-storey homes that met planning regulations and risk reduction measures, were instrumental in enabling flood survivors to live at home, often with access to running water and electricity.

\section{ii. Access to financial capital}

The second dimension of disaster resilience within the plot layer is financial mechanisms that enable poorer people to construct homes of adequate quality. In the Bang Bua Canal savings groups were important mechanisms for poorer people to collectively pool resources in order to access low interest loans. Such loans were then used to re-block plots, reconstruct homes, invest in common infrastructure as well as initiate a social welfare fund. The savings groups worked as a mechanism for building social capital because of the collective ways in which people worked together to manage money. Transparent and accountable processes and management committees earned trust amongst savings group members. Those who did not participate in savings groups either had alternative means of accessing finances (through loans from employers or family members, for example) or felt they could not afford to participate because the investment cost was too high. However, the evidence from the case study suggests that poorer people who participated in collective financial mechanisms were able to afford to transform their individual homes and communal services.

\section{iii. Inclusive planning and reconstruction processes}

Thirdly, the planning policies at a city and neighbourhood scale greatly influence the buildings and services layer. Flexibility in the planning process was important and directly contributed to a more effective building process. Neighbourhoods with permission to legally occupy the land sought special planning permissions. For example, the municipality legally permitted houses in the Bang Bua Canal to be built more closely, waived on-site sanitation regulations and made an exception to Bangkok's Comprehensive Plan's land-use controls (Usavagovitwong et.al., 2013). Moreover, the process of planning, which was run by the neighbourhoods themselves, was flexible and allowed people

to join the programme when they felt ready to.

In summary, analysis of the three case studies at the building layer demonstrates that high quality buildings, access to pro-poor financial mechanisms and flexible planning mechanisms and processes at a neighbourhood and cityscale are key dimensions of disaster resilience within the building layer.

\section{CONCLUSION}

In conclusion, morphology is a useful approach for understanding urban disaster resilience, mainly because the approach assists with the identification of persons at risk, the types of risks they face and whether that person, neighbourhood or city needs to adapt or transform the ways in which different social, economic and governance patterns occur. In summary, disaster resilience is most helpful as a concept when it defines resilience for whom and to what (Sitko, 2016a; Sitko, 2016b).

Crucially, vulnerable communities must be the drivers of adaptation or transformation interventions as demonstrated throughout the four morphological layers of analysis within the case study. Moreover, input from built environment professionals such as urban planners and designers, architects could further strengthen disaster resilience interventions undertaken by local residents. However, it is important that built environment professionals are concerned about disaster and development challenges in equal measure. Vulnerable people do not separate hazards into 'development' and 'disaster' categories and neither must the professionals who design and support the city.

It is argued here, through the example of case study of the Bang Bua Canal, that urban morphology can assist with understanding patterns of social, economic, governance and physical vulnerabilities and capacities within a city. Understanding these patterns provides people with the ability to identify key dimensions of resilience in order for neighbourhoods to 'bounce forward' by addressing the chronic stresses of today and preparing for the inevitable disasters of tomorrow. 


\section{REFERENCES}

Allen, A. et al. 2012, Future Proofing cities: Risks and Opportunities for Inclusive Growth in Developing Countries. London: Atkins.

Almukhtar, A. 2016, Conflict and Urban Displacement, In: Sanderson, D., Kayden, J. and Leis, J. (eds.) Urban Disaster Resilience: New Dimensions from International Practice in the Built Environment, New York: Routledge, 132-141.

Almukhtar, A. (Forthcoming), "Enhancing Place Identity in Historic Cities; The Case of Erbil, Iraq", PhD Thesis, Oxford Brookes University, UK.

Archer, D. 2009, "Social Capital and Participatory Slum Upgrading in Bangkok, Thailand”, PhD Thesis. University of Cambridge, UK.

Arendt, L. and Alesch, D, 2015, Long-Term Community Recovery from Natural Disasters, London: Taylor and Francis Group.

Bolio Arceo, E, 2012, "Urban Transformations and Place-Identity: The Case of Merida, Mexico”, PhD Thesis Oxford Brookes University, UK.

Buchanan-Smith, M. and Fabbri, P., 2005, "Linking Relief, Rehabilitation and Development: A Review of the Debate:,

Watson, B. G. and Bentley, I. 2007, Identity by Design, Oxford: Elsevier.

Carmona, M., Heath, T. and Tiesdell, S. 2003, Public Places Urban Spaces, Oxford: Elsevier.

Christoplos, I., Liljelund, A. and Mitchell, J., 2001, "Re-framing Risk: The Changing Context of Disaster Mitigation and Preparedness", Disasters 25 (3), 185-198.

Combaz, E., 2015, “Disaster Resilience: A Topic Guide”, Birmingham, UK: GSDRC, University of Birmingham.

Conzen, M. P., 2010, “The Elusive Common Denominator in Understanding Urban Form”, Urban Morphology 14(1): 5558.

Dovey, K. and King, R., 2011, "Forms of Informality: Morphology and Visibility of Informal Settlements", Built Environment $37(1): 11-29$.

Folke, C., 2006, "Resilience: The Emergence of a Perspective for Socio-ecological Systems Analysis", Global Environmental Change 16:253-267.

Jacobs, J., 1961, The Death and Life of Great American Cities, New York and Toronto: Random House.

Koster, E., 1998, “Urban Morphology and Computers”, Urban Morphology, 2(1):3-7.

Kropf, K., 2009, “Aspects of Urban Form”, Urban Morphology, 13 (2):105-120.

Kropf, K., 2013, "Evolution and Urban Form: Staking out the Ground for a more Mature Theory", Urban Morphology,17 (2):136-149.

Levine, S. et al., 2012, The Relevance of 'Resilience'? London: Humanitarian Policy Group.

Massey, D., 1993, "Power-geometry and a Progressive Sense of Place", In: Bird, J. et al. (eds.) Mapping the Futures. Local Cultures, Global Change, London: Routledge:59-69.

Pelling, M., 2011, Adaptation to Climate Change: From Resilience to Transformation, Abingdon: Routledge.

Philip, B., 2011, "Bangkok at Risk of Sinking into the Sea”, The Guardian, viewed, 13 September 2011.

Roachanakanan, T., 1999, "Bangkok and the Second Bangkok International Airport: Politics of Planning and Development", $\mathrm{PhD}$ Thesis, Australian National University, Australia.

Journal of Research in Architecture and Planning: Vol. 23, 2017 (Second Issue) 
Sanderson, D. and Sharma, A., 2016, "Making the Case for Resilience”, In: Sanderson, D. and Sharma, A. (eds.), World Disasters Report: Resilience: Saving Lives Today, Investing for Tomorrow. Geneva: IFRC.

Scoones, I., 1998, “Sustainable Rural Livelihoods: A framework for Analysis. Working Paper, 72”, Brighton: Institute for Development Studies.

Sitko, P., 2016a, “Urban Disaster Resilience: Learning from the 2011 Bangkok Flood”, PhD Thesis, Oxford Brookes University,

UK.

Sitko, P., 2016b, "Urban Disaster Resilience: Learning from the 2011 Bangkok", Thailand Flood Using Morphology and Complex Adaptive Systems. In: Sanderson, D., Kayden, J. and Leis, J. (eds.) Urban Disaster: New Challenges for Action. New York: Routledge.

Tanner, T. et al., 2015, Resilience scan 2015 Q1: A Review of Literature, Debates and Social Media on Resilience, London: Overseas Development Institute (ODI).

Twigg, J., 2009, Characteristics of a disaster-resilient community: A guidance note (Version 2), Online: DFID Disaster Risk Reduction Interagency Coordination Group.

Twigg, J., 2015, “Disaster Risk Reduction: New Edition 2015”, Good Practice Review 9, London: HPN.

UN-Habitat, 2011, “Cities and Climate Change: Global Report on Human Settlements 2011”, Washington, DC: UN-Habitat.

UN-Habitat, 2013, "State of the World's Cities 2012/2013”, New York, New York: UN-Habitat.

UNESCAP, 2014, “Bangkok 2011 Flood Case Study”, Bangkok: UNESCAP.

UNISDR, 2015, “The 10 Essentials for Making Cities Resilient”, Online: UNISDR, viewed 30 April 2015, from http://www.unisdr.org/campaign/resilientcities/toolkit/essentials

United Nations Department of Economic and Social Affairs, 2014, "World Urbanisation Prospects", The 2014 Revision, Highlights, New York.

Usavagovitwong, N. et al., 2013, "Housing Density and Housing Preference in Bangkok's Low-Income Settlements", Urbanization and Emerging Population Issues Working Paper 12, International Institute for Environment and Development (IIED), London.

Warner, S. and Whittenmore, A., 2012, American Urban Form: A Representative History, Cambridge, MIT Press.

Whitehand, J., 1987, The Changing Face of Cities: A Study of Development Cycles and Urban Form, Oxford: Basil Blackwell.

Whitehand, J., 2001, “British Urban Morphology: The Conzenian Tradition”, Urban Morphology 5 (2): $103-109$.

World Bank, 2010, “Climate Risks and Adaptation in Asian Coastal Megacities”, Washington DC, The World Bank.

World Bank, 2015, “East Asia's Changing Urban Landscape: Measuring a Decade of Spatial Growth”, Urban Development Series, Washington, DC: World Bank.

Wungpatcharapon, S. and Tovivich, S., 2012, “Baan Monkong at Klong Bang Bua Community Guidebook”, Bangkok: Community Organisation Development Institute, Community Act Network, Asian Coalition for Housing Rights. 